\title{
VALORES DE ALGUNAS DETERMINACIONES INMUNOLOGICASS NORMALES EN NUESTRO MEDIO
}

\author{
Dr. Sergio Barba \\ Servicio de Inmunología y Alergia HG-1, Quito \\ Sr. Víctor H. Proaño G. \\ Dr. Alfredo Carrera
}

El impulso y la importancia de la inmunología en la valoración de algunos enfermos ha tenido gran avance en los últimos tiempos. Actualmente no se discute el valor que tiene: la determinación de inmunoglobulinas, de fracciones de complemento, $\mathrm{y}$ otros parámetros para los cuales han demostrado ser efectivas las técnicas inmunológicas; pero, surge el problema de la técnica y el ajuste de esa técnica al medio, así como la correcta interpretación de los resultados. De ahí que es importante el establecimiento de ciertos procedimientos normalizados para obtener iguales resultados con el mismo método, así como también el conocer los datos que pueden ser considerados como normales y aplicarlos correctamente.

Entonces, el estudio preliminar que fresentamos, le consideramos de mucha inportancia por ser la primera vez que se realiza en nuestro medio.

I. MATERIAL Y METODOS:

Se analizaron 623 determinaciones in. munológicas en personas consideradas como "normales" o pacientes con afecciones que no tenían compromiso inmunológico evidente de la población que concurre al Hospital General de las FF. AA. de la ciudad de Quito. Estas determinaciones se las hace a 3 grupos de pacientes: $1-12$ años, de $13-60$ años, y de más de 60 años respectivamente.

Las determinaciones que se realizan son: la valoración de inmunoglobinas ig $\mathrm{G}$ ig $\mathrm{A}$, e ig $\mathrm{M}$ en suero; Ig $\mathrm{A}$ en saliva; $\mathrm{C}_{3} \mathrm{c}$ y alfa ${ }^{1}$ antitripsina en suero, por inmunodifusión, de la siguiente manera:

1.-Para la determinación de $\mathrm{Ig} \mathrm{G}$, Ig A e Ig M séricas se utiliza el método de inmunodifusión radial simple, en placas Partigen (**): luego de extraída la sangre por punción venosa, se separa el suero por centrifugación, $y$, en cantidad de 5 microlitros se deposita en los orificios del disco, incubándolos luego a temperatura ambiente por 48 ho-

(**:) Reactivos Behrinwerke. 
ras, a partir de las cuales se hace la lectura calculando el área de precipitado de acuerdo con la siguiente fórmula:

$$
d^{2} \times \text { dilución }
$$

en la que d es el diámetro del halo de difusión, multiplicado por la dilución del suero. Este valor se lleva al sistema de ordenadias establecido mediante la valoración de los testigos con cantidad conocida de inmunoglobulinas, y se establecen los valores respectivos.

2--Para la determinación de $\mathrm{C}_{3} \mathrm{c}$, la dilución del suero es de 1,2.

3. - Para la de alfa ${ }^{1}$ antitripsina no se efectúa dilución alguna de la mues. tra. La lectura se hace exactamente siguiendo el mismo procedimiento anteriormente descrito.

4.-Para Ig A en saliva, se toman 20 microlitros de saliva en ayunas, se depositan en discos LC Partigen que contienen Anti Ig A, y para su lectura se procede en igual forma que en las anteriores.

\section{RESULTADOS:}

Nuestro grupo de pacientes por edad se organizó de la siguiente manera:

\section{TABLA $\mathbb{N}^{\circ} 1$}

\section{EDAD DE LA MUESTRA EN ESTUDIO}

$\begin{array}{rrr}1-12 \text { años } & 168 & 26.97 \% \\ +13-60 \text { años } & 422 & 67.74 \% \\ + \text { de } 60 \text { años } & 33 & 5.29 \% \\ \text { TOTAL } & 623 & 100 \%\end{array}$

Los valores de Inmunoglobulinas séricas (Ig), para estas edades se establecen en las siguientes tablas:

TABLA No 2

VALORES DE Ig SERICAS (*) EN EL GRUPO DE 1-12 AÑOS (*) ( $n=23)$

$\begin{array}{lccccc} & \text { Promedio } & \text { Mediana } & \text { D. Est. } & \text { Ent. Conf. 99\% } & \text { C. Pearson } \\ \text { IgG } & 1712 & 1645 & 922.35 & 1205-2219 & 0.15 \\ \text { IgA } & 252.82 & 225 & 157.81 & 166-340 & -0.87 \\ \text { IgM } & 209.13 & 210.5 & 109.46 & 151-268 & 0.72\end{array}$




\section{TABLA N 3}

VALORES DE Ig SERICAS (*) EN EL GRUPO DE 13-60 AÑOS (*) ( $n=132$ )

$\begin{array}{lccccc} & \text { Promedio } & \text { Mediana } & \text { D. Est. } & \text { Int. Conf. 99\% } & \text { C. Pearson } \\ \text { IgG } & 1688.27 & 1583.33 & 726.49 & 1421-1955 & 0.62 \\ \text { IgA } & 297.15 & 272 & 168.89 & 235-360 & 0.74 \\ \text { IgM } & 221.71 & 215 & 118.61 & 178-266 & 0.23\end{array}$

TABLA No 4

VALORES DE Ig SERICAS (*) EN EL GRUPO MAYOR $D E 60$ AÑN $O S(\mathrm{n}=24)$

$\begin{array}{lccccc} & \text { Promedio } & \text { Mediana } & \text { D. Est. } & \text { Int. Conf. 99\% } & \text { C. Pearson } \\ \text { IgG } & 2053 & 1945 & 793.96 & 1626-2479 & -0.16 \\ \text { IgA } & 249.99 & 202.5 & 193.09 & 141-359 & 0.64 \\ \text { IgIM } & 177.04 & 92 & 69.74 & 69-145 & 0.96\end{array}$

La determinación de IgA en saliva trae los siguientes resultados:

\section{TABLA N 5}

VALORES DE IgA EN SALIVA EN EL GRUPO DE 1-12 AÑOS (*) (n=61)

Promedio Mediana

Ig As

6.91

5.05
D. Est.

4.88

5.41-9.42
C. Pearson

0.54

TABLA No 6

VALORES DE IgA EN SALIVA EN EL GRUPO DE 13-60 AÑOS (*) ( $n=94$ )

$\begin{array}{rrrrrrr} & \text { Promedio } & \text { Mediana } & \text { D. Est } & \text { Int. Conf. 99\% } & \text { C. Pears } \\ \text { Ig As } & 10.39 & 9.2 & 6.8 & 7.97-12.08 & -0.02\end{array}$

(*) En mg\%
Observación: En todas las tablas se presenta un intervalo de confianza que es del $99 \%$ Los valores de la fracción 3 de Complemento $\left(\mathrm{C}_{3} \mathrm{c}\right)$ se presentan de la siguiente manera: 
TABLA N $N^{0} 7$

VALORES DE $C_{3}$ C SERICO EN EL GRUPO DE 1-12 AÑOS (*) (n=52)

$\begin{array}{lcccrr} & \text { Promedio } & \text { Mediana } & \text { D. Est. } & \text { Int. Conf. 99\% } & \text { C. Pearson } \\ \mathrm{C}_{3} \mathrm{C} & 105.57 & 105 & 52.47 & 87.83-123.30 & -0.08\end{array}$

TABLA N $\div 8$

VALORES DE $\mathrm{C}_{3} \mathrm{C}$ SERICO EN EL GRUPO DE 13-60 AÑNOS (*) ( $\mathrm{n}=152$ )

$\begin{array}{cccccc} & \text { Promedio } & \text { Mediana } & \text { D. Est. } & \text { Int. Conf. 99\% } & \text { C. Pearson } \\ \mathrm{C}_{3} \mathrm{C} & 107.55 & 103 & 40.55 & 93.53-121.56 & 0.09\end{array}$

La investigación de los niveles normales de -1 antitripsina se muestran en las siguientes tablas:

TABLA No 9

VALORES DE ALFA-1 ANTITRIPSINA EN EL GRUPO DE $12 \operatorname{ANOS}(*)(\mathrm{n}=32)$
Promedio
Mediana
D. Est.
Int. Conf. $99 \%$
C. Pearson

Alfa-1 anti-

tripsina $\quad 386.09$

370

17.2 .80

$310-462$

0.90

\section{TABLA No 10}

VALORES DE ALFA-1 ANTITRIPSINA EN EL GRUPO DE 13-60 AÑOS (*) $(\mathrm{n}=44)$
Promedio
Mediana
D. Est.
Int. Conf. $99 \%$
C. Pearson

Alfa-1 anti-

tripsina $\quad 434.05$ 
TABLA No 11

VALORES DE ALFA-1 ANTITRIPSINA EN EL GRUPO DE $M A S$ DE 60 AÑ $O S(*)(\mathrm{n}=9)$
Promedio
Mediana
D. Est .
Int. Conf. $99 \%$
C. Pearson

Alfa-1 antitripsina

370

370

110

$250-480$

0.15

(*): $\operatorname{En} \mathrm{mg} \%$

\section{DISCUSION Y}

\section{CONCLUSIONES:}

No tiene este trabajo la intención de establecer la importancia de los parárnetros inmunológicos citados. En la investigación, lo que se trata es de dar el primer paso para la "normalización" de los procedimientos y de obtener los primeros valores normales de referencia en nuestro país.

En primer lugar, tenemos que estar de acuerdo en que las condiciones nutricionales y socio-económicas dé nuestros pobladores no son semejantes a las existentes en Europa o EE. UU., que es en donde se fabrica los reactivos y nos envían los datos de normalidad referencial. Se dice que la desnutrición es un determinante importante dentro de la Capacidad Inmunológica, (1) afectando especialmente a la respuesta inmune celular; y ahora, ya conocemos también que hay una enorme interrelación celular-humoral moduladora de la producción de anticuerpos $(2,3)$.

Con todas estas consideraciones, se concluye lo siguiente:

1.-Con los datos obtenidos podemos inferir que, los valores de inmuno.. gloibulinas séricas Ig $\mathrm{G}, \mathrm{Ig} \mathrm{A}$ e ig $\mathrm{M}$ son algo más elevados que los de personas europeas o americanas, y están entre:

IgG: $\quad 1421-1955 \quad \mathrm{mg} \%$

IgA: $\quad 235-360 \quad \mathrm{mg} \%$

IgM: $\quad 178-266 \quad \mathrm{mg} \%$

aumento que es más notorio especialmente a nivel de las cifras bajas. Un hecho importante, es que las cifras de inmunoglobulinas en nuestro medio aumentan con la edad.

2.- Las cifras de Ig A en saliva, que suponemos en su mayoría corresponde a Ig A secretora, oscilan en valores comprendidos entre 5 y 12 $\mathrm{mg} \%$ en nuestro medio y en nuestro tipo de personas en estudio, cifras que posiblemente aumentan también con la edad. 
3.-La fracción 3 de complemento, mediante esta técnica, oscila entre 80 y $120 \mathrm{mg} \%$, la cual igualmente es algo más superior en sus niveles bajos que las cifras enviadas por la casa productora del reactivo. Aparentemente, no hay relación entre la edad de los pacientes y la cantidad de complemento.

4.- - La proteasa alfa-1 antitripsina hace una curva de aumento, cuyo acmé corresponde a la edad adulta, y los valores "normales" oscilan entre 382 y $486 \mathrm{mg} \%$, que comparativamente, también sigue la misma tónica de incremento notada en las inmunoglobulinas, en relación a las cifras consideradas normales oin otros países.

\section{RESUMIEN}

Se analizan 678 determinaciones inmunológicas en personas sanas o con otras afecciones sin compromiso inmunológico, que concurren al Hospital General de las Fuerzas Armadas, de Quito.

Por el método de inmunodifusión radial se dosifican las inmunoglobulinas
G, A y $M$ en el suero; IgA en saliva; valores de $\mathrm{C} 3$ y alfa-1 antitripsina en el suero.

Los valores obtenidos tienen buena correlación estadística y se les ha clasificado en tres grupos de edades: de O-12; de 13-60 años y de más de 60, en relación a épocas de la vida influyentes en la madurez inmunológica de las personas. Estos demuestran que los lím:tes inferiores de las cifras son mayores en nuestra población en la determinación de inmunoglobulinas, complemento, alfa-1 antitripsina. Los valores altos son concordantes con los de referencia internacional.

\section{BIBLIOGRAFIA:}

1 Barba, S.: Los Síndromes rino-sinu-bronquiales en el Ecuador, en Prenas, 1982.

2 Welliver RC, et al: Cell-mediated immune response to respiratory syncytial virus infection: relationship to the development of reactive airway disease. J. Pediatr 94: 370, 1979.

3 Barba, S. y García M.: Inmunología de ia tuberculosis: tuberculina y BCG en el Hospital General de las FF. AA., Hosp. Gral. FF. AA. 3: 49, 1981. 